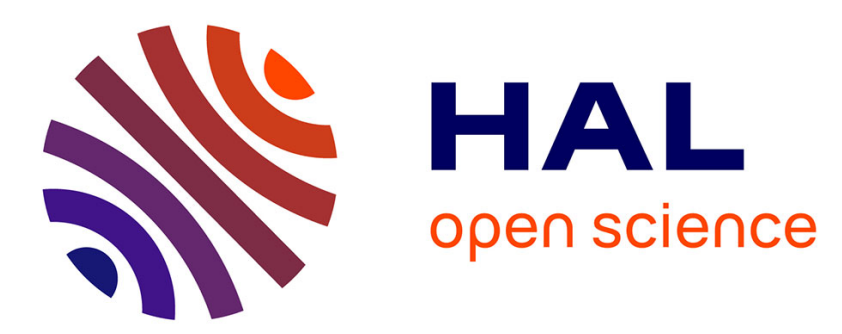

\title{
Crystallisation of a highly metastable hydrated calcium pyrophosphate phase
}

Pierre Gras, Sébastien Teychené, Christian Rey, Cédric Charvillat, Béatrice Biscans, Stéphanie Sarda, Christèle Combes

\section{- To cite this version:}

Pierre Gras, Sébastien Teychené, Christian Rey, Cédric Charvillat, Béatrice Biscans, et al.. Crystallisation of a highly metastable hydrated calcium pyrophosphate phase. CrystEngComm, 2013, vol. 15, pp. 2294-2300. 10.1039/C2CE26499D . hal-00917720

\author{
HAL Id: hal-00917720 \\ https://hal.science/hal-00917720
}

Submitted on 12 Dec 2013

HAL is a multi-disciplinary open access archive for the deposit and dissemination of scientific research documents, whether they are published or not. The documents may come from teaching and research institutions in France or abroad, or from public or private research centers.
L'archive ouverte pluridisciplinaire HAL, est destinée au dépôt et à la diffusion de documents scientifiques de niveau recherche, publiés ou non, émanant des établissements d'enseignement et de recherche français ou étrangers, des laboratoires publics ou privés. 


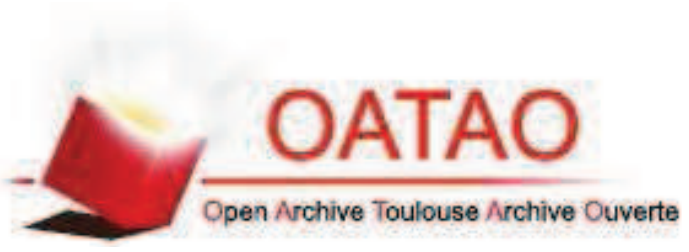

\section{Open Archive TOULOUSE Archive Ouverte (OATAO)}

OATAO is an open access repository that collects the work of Toulouse researchers and makes it freely available over the web where possible.

This is an author-deposited version published in : http://oatao.univ-toulouse.fr/ Eprints ID : 9381

To link to this article : DOI:10.1039/C2CE26499D

URL : http://dx.doi.org/10.1039/C2CE26499D

To cite this version :

Gras, Pierre and Teychené, Sébastien and Rey, Christian and Charvillat, Cédric and Biscans, Béatrice and Sarda, Stéphanie and Combes, Christèle Crystallisation of a highly metastable hydrated calcium pyrophosphate phase. (2013) CrystEngComm, vol. 15 ( $\mathrm{n}^{\circ}$ 12). pp. 2294-2300. ISSN 1466-8033

Any correspondance concerning this service should be sent to the repository administrator: staff-oatao@listes-diff.inp-toulouse.fr 


\title{
Crystallisation of a highly metastable hydrated calcium pyrophosphate phase
}

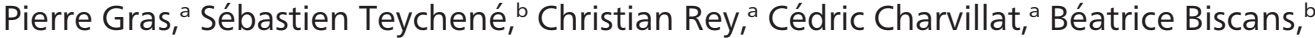 \\ Stéphanie Sardac and Christèle Combes*a

\begin{abstract}
A simple and fast synthesis method was set up to obtain pure hydrated calcium pyrophosphate (CPP) phases of biological interest. This work focused on a specific phase synthesised at $25^{\circ} \mathrm{C}$ and $\mathrm{pH} 4.5$ in a stirred tank reactor. Powder X-ray diffraction, FTIR spectroscopy, scanning electron microscopy and thermogravimetric analyses revealed that the phase is unknown but presents similarities with a monoclinic tetrahydrated CPP phase $\left(\mathrm{Ca}_{2} \mathrm{P}_{2} \mathrm{O}_{7} \cdot 4 \mathrm{H}_{2} \mathrm{O}, \mathrm{m}\right.$-CPPT $\beta$ phase) synthesised under the same conditions of $\mathrm{pH}$ and temperature. Characterisation of the unreferenced phase (u-CPP) has been performed, especially to better identify its composition, structure and stability, as well as its possible relation to the $\mathrm{m}$-CPPT $\beta$ phase or to other hydrated CPP phases.
\end{abstract}

\section{Introduction}

Osteoarthritis (OA) is the most common form of rheumatic disease, leading ultimately to chronic pain and disability for the patient. Calcium pyrophosphate (CPP) dihydrate crystals (CPPD, $\mathrm{Ca}_{2} \mathrm{P}_{2} \mathrm{O}_{7} \cdot 2 \mathrm{H}_{2} \mathrm{O}$ ) have been observed in the interarticular spaces of arthritic patients and appear to induce an inflammatory response. Up to now current treatments are not able to inhibit the formation of CPP crystals.

Two polymorphs of CPPD have been identified in vivo: a triclinic form (t-CPPD) ${ }^{1}$ and a monoclinic form (m-CPPD). ${ }^{2}$ In addition to $\mathrm{m}$ - and t-CPPD phases, other hydrated calcium pyrophosphate phases have been prepared in vitro, including a third dihydrated supposedly hexagonal polymorph (h-CPPD $)^{2}$ and a dimorphic monoclinic tetrahydrate (CPPT, $\mathrm{Ca}_{2} \mathrm{P}_{2} \mathrm{O}_{7}$. $4 \mathrm{H}_{2} \mathrm{O}$ ) referred to as m-CРPT $\alpha^{3}$ and m-CPPT $\beta .{ }^{4}$

The syntheses reported in the scientific literature are based on dissolution of an intermediate, amorphous CPP (a-CPP) or calcium dihydrogen pyrophosphate $\left(\mathrm{CaH}_{2} \mathrm{P}_{2} \mathrm{O}_{7}\right)$, and on crystallisation using different synthesis conditions $(\mathrm{pH}$, temperature, concentration, agitation). These parameters have been described as having a great influence on the phase and the size of the synthesised crystals. ${ }^{2,5-7}$ The solubility constants of CPP compounds have been reported to be low $\left(\mathrm{p} K_{\mathrm{s}}(\mathrm{m}-\mathrm{CPPT} \beta)=17.1\right),{ }^{8}$ leading to solutions with high supersaturation rates during the synthesis. Thus, the addition of reactants and their mixing during the synthesis play

${ }^{a}$ CIRIMAT, INPT-CNRS-UPS, Université de Toulouse, ENSIACET, Toulouse, France E-mail: christele.combes@ensiacet.fr; Fax: +33 534323498; Tel: +33 534323409 ${ }^{b}$ Laboratoire de Génie Chimique, INPT-CNRS-UPS, Université de Toulouse, ENSIACET, Toulouse, France

${ }^{c}$ CIRIMAT, INPT-CNRS-UPS, Université de Toulouse, Université Paul Sabatier, Toulouse, France important roles in homogenising the solution and controlling the different steps of the precipitation: nucleation and crystal growth. ${ }^{9-11}$ However, to the best of our knowledge on CPP compounds preparation, agitation mode has not been studied as a parameter influencing the phase synthesised.

There is an interest in studying the conditions of formation of all these hydrated CPP phases and in finely characterising. them in order to better understand the formation of the hydrated CPP phases encountered in vivo (direct formation or hydrolysis and evolution of a metastable precursor phase).

Among these phases, the present work will focus on the preparation and characterisation of a metastable hydrated CPP phase formed at $25{ }^{\circ} \mathrm{C}$ and acidic pH (4.5) in a stirred tank reactor. Comparisons are made with a close pyrophosphate mineral, m-CPPT $\beta$, produced under the same concentration and temperature conditions.

\section{Experimental section}

\section{Materials}

Hydrated calcium pyrophosphate phases were synthesised by double decomposition mixing a potassium pyrophosphate solution and a calcium nitrate solution.

Anhydrous tetrapotassium pyrophosphate $\left(\mathrm{K}_{4} \mathrm{P}_{2} \mathrm{O}_{7}\right)$ was obtained by heating $100 \mathrm{~g}$ of dipotassium phosphate $\left(\mathrm{K}_{2} \mathrm{HPO}_{4}\right.$, VWR, $100 \%$ purity) in a muffle furnace at $400{ }^{\circ} \mathrm{C}$ for $3 \mathrm{~h}$.

Calcium nitrate tetrahydrate salt $\left(\mathrm{Ca}\left(\mathrm{NO}_{3}\right)_{2} \cdot 4 \mathrm{H}_{2} \mathrm{O}\right.$, Carlo Erba, $97 \%$ purity), acetic acid solution (VWR, 100\% purity) and ammonia solution (VWR, 30\%) were used as received without further purification.

All solutions were prepared using de-ionised water. 


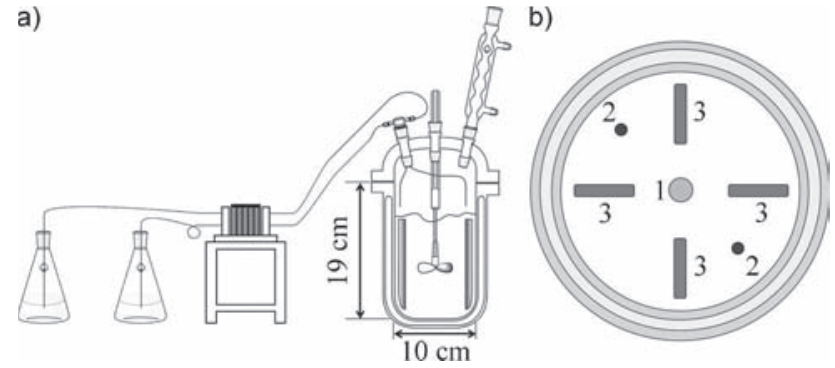

Fig. 1 a) Standard configuration of the precipitation devices. b) Positions of the marine propeller (1), the feeding (2) and the baffles ( 3 ) in the reactor, top view.

\section{Experimental devices}

The experiments were carried out in a $1 \mathrm{~L}$ round-bottomed Pyrex glass crystalliser. The double-jacketed crystalliser was equipped with a lid, four baffles, a condenser and a Pt-100 resistance thermometer (Fig. 1). The temperature of the crystalliser was controlled by a programmable thermostatic bath. Mixing was ensured by a marine propeller. For all the experiments, the stirring rate was $400 \mathrm{rpm}$.

A peristaltic pump (Minipuls 3, Gilson Inc.) with $2.79 \mathrm{~mm}$ diameter Tygon tubing was used to add the reactants during the synthesis (Fig. 1).

\section{Synthesis}

A buffer solution at $\mathrm{pH} 4.5$ was prepared by adding $12 \mathrm{~mL}$ of acetic acid and $25 \mathrm{ml}$ of ammonia solution to $400 \mathrm{~mL}$ of water.

Two reagent solutions were obtained by adding $\mathrm{K}_{4} \mathrm{P}_{2} \mathrm{O}_{7}(5.00$ g, i.e. $\left.1.51 \times 10^{-2} \mathrm{~mol}\right)$ and $\mathrm{Ca}\left(\mathrm{NO}_{3}\right)_{2} \cdot 4 \mathrm{H}_{2} \mathrm{O}(7.16 \mathrm{~g}$, i.e. $3.03 \times$ $10^{-2} \mathrm{~mol}$ ) to $200 \mathrm{ml}$ of water, respectively. Solutions were stirred vigorously at room temperature until the solid was completely dissolved.

The double decomposition of the reagent solutions was performed in a stirred tank reactor at $25{ }^{\circ} \mathrm{C}$. The reagent solutions were added continuously and simultaneously into the buffer solution at a constant volumetric flow rate $(4.5 \mathrm{~mL}$ $\min ^{-1}$ ) using a peristaltic pump.

After addition was completed, the precipitate formed was left in solution during $10 \mathrm{~min}$ at $25{ }^{\circ} \mathrm{C}$, then filtered using a Büchner funnel and washed 3 times with de-ionised water before finally being dried overnight in an oven at $37{ }^{\circ} \mathrm{C}$.

The samples were kept in a sealed vial at room temperature; no evidence of phase alteration was noticed over 1 month.

Similar experiments were carried in a $1 \mathrm{~L}$ Erlenmeyer flask with the same synthesis protocol and are considered in this paper as reference.

\section{Characterisation}

Powder X-ray diffraction (XRD) measurements were carried out using a PANanalytical $\mathrm{X}$-ray generator with a Co $\mathrm{K} \alpha$ radiation $\left(\mathrm{Co} \mathrm{K} \alpha_{1} \lambda=1.78901 \AA\right.$ and Co $\mathrm{K} \alpha_{2} \lambda=1.79290 \AA$ ), a graphite monochromator and a curved position-sensitive detector Inel CPS 120 diffractometer. The XRD patterns were obtained after $3 \mathrm{~h}$ of recording in the $2 \theta$ range: $10^{\circ}-120^{\circ}$ at $298 \mathrm{~K}$.

FTIR spectra were recorded with a Thermo Nicolet 5700 Fourier-transform infrared spectrometer in the $4000-400 \mathrm{~cm}^{-1}$ wavelength range with 64 scans accumulation and $4 \mathrm{~cm}^{-1}$ resolution using powder samples in $\mathrm{KBr}$ pellets ( $2 \mathrm{mg}$ sample per $300 \mathrm{mg} \mathrm{KBr}$ ).

Thermogravimetric analyses (TGA-DTA) were performed using a Setaram Instrumentation Setsys evolution system, with a heating rate of $5{ }^{\circ} \mathrm{C}$ per minute, starting at $30{ }^{\circ} \mathrm{C}$ up to $500{ }^{\circ} \mathrm{C}$.

Scanning electron microscopy (SEM) micrographs were obtained using a Leo 435 VP microscope at an accelerating voltage of $7 \mathrm{kV}$. Sample were silver plated before observation.

Phosphate concentrations were measured using a standard spectrophotometric determination of the yellow phosphovanadomolybdic acid complex using a Hitachi U-1100 spectrometer set at $460 \mathrm{~nm}$. Pyrophosphate concentrations were determined after hydrolysis of pyrophosphate ions into phosphate ions at $100{ }^{\circ} \mathrm{C}$ in acidic medium. Then phosphate ions were titrated as described above.

Crystallographic lattice constants were determined using Jana2006 software (version 01/07/2011 ${ }^{12}$ ). The pseudo-Voigt shape function was assumed and the background was determined manually. Refinement of the parameters was performed in the following order: scale factor, zero shift, cell parameters, profile parameter and asymmetry parameter. The total number of variables refined was 9 .

\section{Results and discussion}

\section{Synthesis}

All reagents were stable for more than 6 months if stored in a dry place; they were easily soluble in water. An XRD diagram of anhydrous tetrapotassium pyrophosphate showed no evidence of dipotassium phosphate traces and characteristic vibrational modes of $\mathrm{P}_{2} \mathrm{O}_{7}{ }^{4-}$ ions were observed at $882.0 \mathrm{~cm}^{-1}$ on FTIR spectra (data not presented).

The synthesis in aqueous buffered medium we set up was based on the following chemical reaction equation (1) in water:

$$
2 \mathrm{Ca}^{2+}+\mathrm{P}_{2} \mathrm{O}_{7}{ }^{4-} \rightarrow \mathrm{Ca}_{2} \mathrm{P}_{2} \mathrm{O}_{7} \cdot n \mathrm{H}_{2} \mathrm{O}
$$

Whether performed in a stirred tank reactor or in an Erlenmeyer flask, the synthesis of the hydrated CPP phase was carried out without intermediates and led to a white precipitate with a reaction yield greater than $90 \%$.

The $\mathrm{pH}$ was measured before and after the synthesis and found to be stable for each experiment. The temperature and the volumetric flow rate of reagents were kept stable during all the experiments. The influence of these three parameters was studied and several calcium pyrophosphate compounds were synthesised using different experimental conditions; the full study on the effect of these parameters will be presented in another paper.

\section{Characterisation}

The products were characterised "as synthesised" whether the syntheses were performed in a stirred tank reactor or in an Erlenmeyer flask. The phase produced in the Erlenmeyer flask 

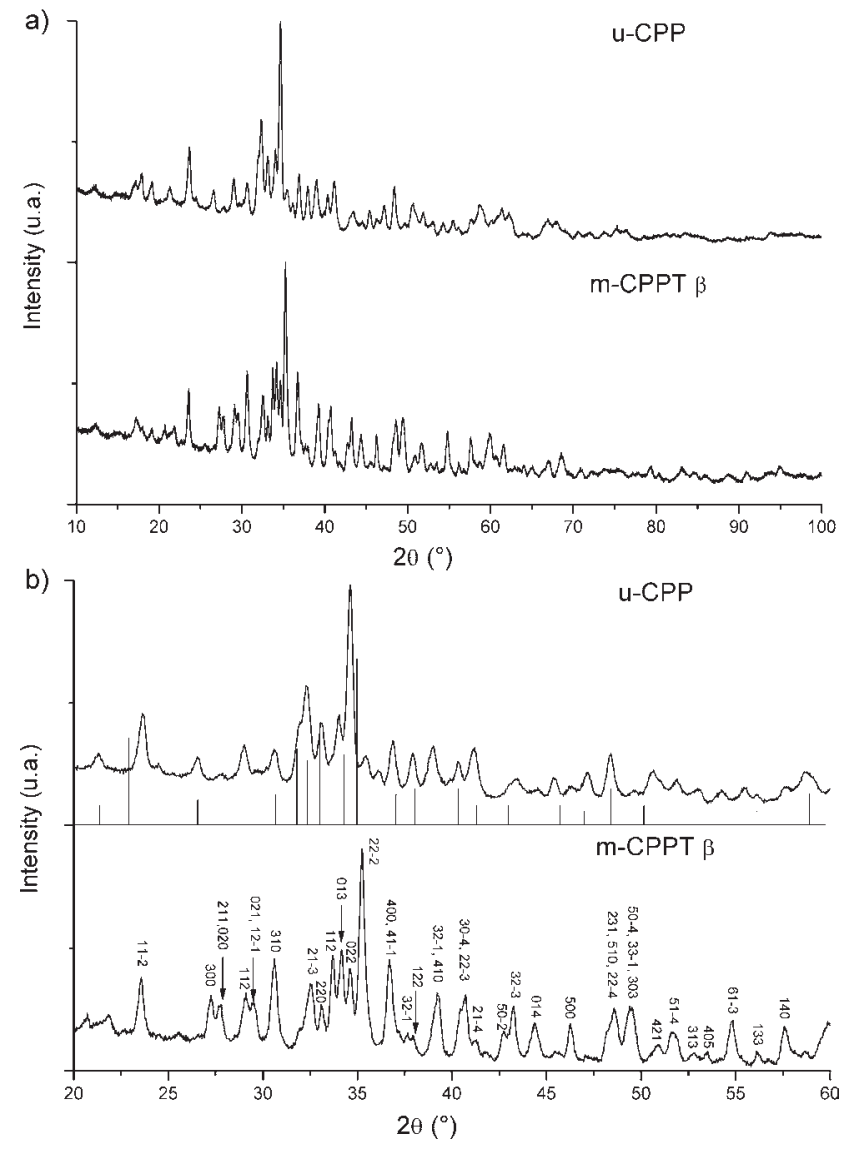

Fig. 2 XRD patterns of the two hydrated calcium pyrophosphate phases synthesised using two different setups: a) in the $2 \theta=10-100^{\circ}$ domain; $b$ ) in the $2 \theta=20-60^{\circ}$ domain (bars under u-CPP diagram correspond to the diagram of h-CPPD phase reported by Mandel $^{2}$ ).

was identified by powder X-ray diffraction analysis as being pure $\mathrm{m}$-CPPT $\beta$ phase, whereas the diagram scattered by the phase produced within the stirred tank reactor did not match the patterns of any of the 25 calcium pyrophosphate compounds referenced (Fig. 2a). ${ }^{7}$ This unreferenced phase will be referred to as u-CPP in this article. If we focus in the $2 \theta$ $=20-60^{\circ}$ domain (Fig. $2 \mathrm{~b}$ ), we notice that among the known CPP phases, the diagram of the $\mathrm{u}$-CPP phase presents some analogies with that of the h-CPPD phase. h-CPPD has been described by Mandel et al., ${ }^{2}$ as a phase obtained from m-CPPT $\beta$ by dehydration under vacuum.

The method set up for m-CPPT $\beta$ phase synthesis is faster than the methods already published: syntheses achieved within $45 \mathrm{~min}$ compared to $24 \mathrm{~h}$ to 1 week for previously published methods. ${ }^{2,7,8}$ The same conditions of concentration and temperature were already known to lead to the m-CPPT $\beta$ phase (temperature below $50{ }^{\circ} \mathrm{C}, \mathrm{pH}$ above 5) but the influence of the agitation has not been elucidated.

In order to further characterise this unknown u-CPP phase, several complementary analytical techniques were used to provide information about the new phase structure.

It shall be recalled that the hydrolysis of pyrophosphate ions might lead to the formation of orthophosphate anions
$\left(\mathrm{HPO}_{4}{ }^{2-}\right.$ and $\left.\mathrm{PO}_{4}{ }^{3-}\right)$ according to the following reversible chemical reaction (2):

$$
\mathrm{P}_{2} \mathrm{O}_{7}{ }^{4-}+\mathrm{H}_{2} \mathrm{O} \rightleftharpoons 2 \mathrm{HPO}_{4}{ }^{2-}
$$

This reaction could occur for hydrated CPP phases in two different ways as a crystalline process or in the synthesis solution. Water molecules held in the structure could generate an internal hydrolysis at high temperature, ${ }^{13}$ but the phenomenon is negligible at ambient temperature. External hydrolysis in acidic aqueous medium has been also reported and could occur in significant amounts during synthesis or titration of CPP phases even without another catalyst than $\mathrm{H}_{3} \mathrm{O}^{+}{ }^{14}$ Nevertheless, phosphate titration results indicated that pyrophosphate hydrolysis either did not occur or occurred in insufficient quantity to be detected: $1 \%$ of the total $\mathrm{P}_{2} \mathrm{O}_{7}{ }^{4-}$ ions were titrated as being hydrolysed, which corresponds to the detection limit of the method. Indeed, a portion of the pyrophosphate could have been hydrolysed during the sample preparation used for the titration of orthophosphate ions, as a consequence of dissolution of the sample carried out in acidic medium. The titration of pyrophosphate indicated $20.2 \mathrm{wt} \%$ of phosphorus in the as-synthesised u-CPP phase, and $19.1 \mathrm{wt} \%$ of phosphorus in the as-synthesised m-CPPT $\beta$ phase which correspond closely to the theoretical content (respectively 20.1 wt $\%$ and $19.0 \mathrm{wt} \%$ ) (Table 1).

In the absence of catalyst, the hydrolysis reaction of pyrophosphate ions occurs extremely slowly at low temperature, and the present synthesis conditions (temperature and duration) do not allow significant advancement of this reaction.

Fig. 3 shows the particle morphologies of the two phases synthesised. Both m-CPPT $\beta$ and u-CPP crystals are assembled as oval shaped plates. Platelets of the $\mathrm{u}$-CPP phase (Fig. $3 \mathrm{~b}$ ) are smaller, with size up to $4 \mu \mathrm{m}$, thinner and more agglomerated than those observed for m-CPPT $\beta$, leading to a sand rose flower organisation.

The difference in morphology between the two phases could probably be attributed to the mixing conditions during synthesis. The morphology and size of m-CPPT $\beta$ crystals have already been reported to vary widely, depending on the protocol for their synthesis. However the plate-like morphology of this phase was related to the layered structure of m-CPPT $\beta$ determined by Balić-Žunić et $a l . ;^{4}$ this feature suggests there could be a link between the structures of these two phases.

The different structures of the calcium pyrophosphate hydrates elucidated indicate significant differences in the environment of the pyrophosphate ions. ${ }^{1,3,4}$ In particular, the $\mathrm{P}-\mathrm{O}-\mathrm{P}$ angle of the anion could change from $123.1^{\circ}$ for the

Table 1 Phosphorus content (as $\mathrm{P}_{2} \mathrm{O}_{7}{ }^{4-}$ or $\mathrm{PO}_{4}{ }^{3-}$ ions; wt\%) in the assynthesised hydrated CPP phases

\begin{tabular}{lll}
\hline & $\mathrm{P}$ as $\mathrm{P}_{2} \mathrm{O}_{7}{ }^{4-}(\mathrm{wt} \%)$ & $\mathrm{P}$ as orthophosphate (wt\%) \\
\hline u-CPP & 20.2 & 0.22 \\
m-CPPT $\beta$ & 19.1 & 0.23
\end{tabular}



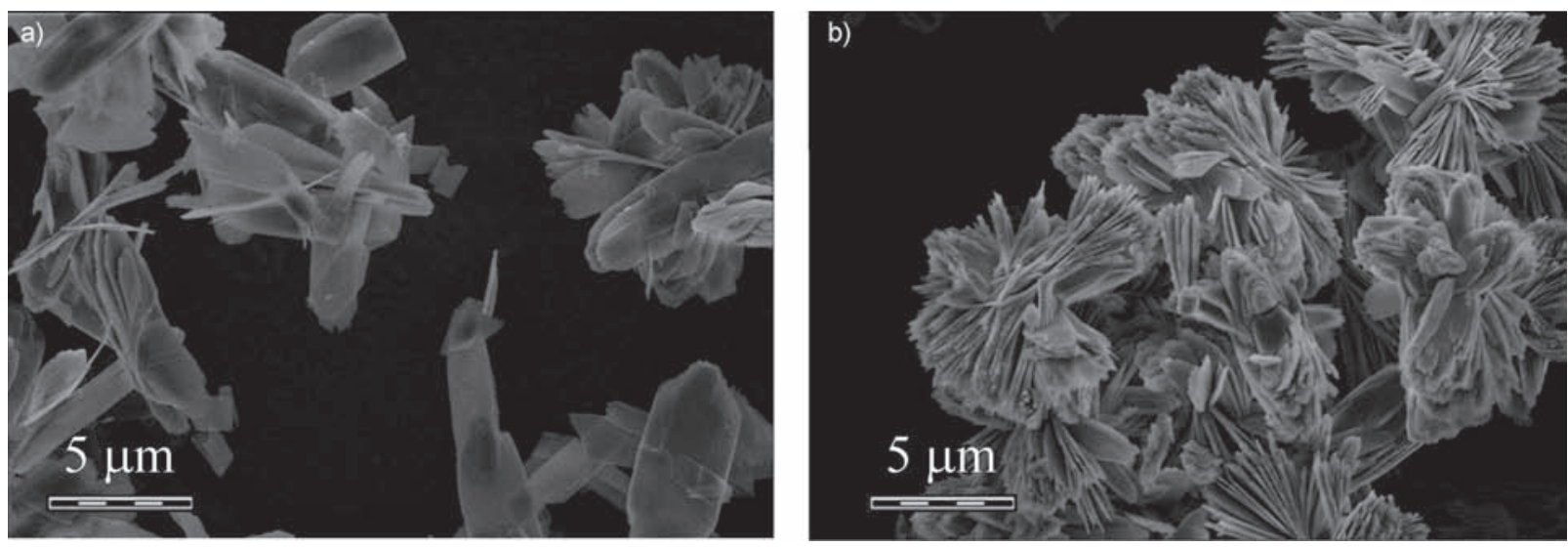

Fig. 3 SEM micrographs of the two hydrated calcium pyrophosphate phases synthesised under the same conditions but using two different setups: a) m-CPPT $\beta$; b) u-CPP.

$\mathrm{t}$-CPPD phase to $134^{\circ}$ for $\mathrm{m}$-CPPT $\beta$. Differences are also observed for the $\mathrm{P}-\mathrm{O}$ distances.

FTIR spectroscopy could also be an important characterisation technique for calcium pyrophosphate hydrates, with the geometry of the ion affecting the bands observed on the spectrum. Each compound provides a specific spectrum. However, FTIR spectroscopy analysis did not allow us to substantially distinguish the two CPP phases synthesised: the $\mathrm{P}-\mathrm{O}$ and $\mathrm{P}-\mathrm{O}-\mathrm{P}$ vibration bands between 1250 and $500 \mathrm{~cm}^{-1}$ are similar, although a faint difference can be noticed in their water $\mathrm{O}-\mathrm{H}$ vibration domains between $2800 \mathrm{~cm}^{-1}$ and 3700 $\mathrm{cm}^{-1}$ (Fig. 4a).

The lack of a vibration band for the $\mathrm{P}-\mathrm{O}$ bond beyond 1200 $\mathrm{cm}^{-1}$ indicate the absence of $\mathrm{HP}_{2} \mathrm{O}_{7}{ }^{3-}$ ions in the crystal. $\mathrm{HP}_{2} \mathrm{O}_{7}{ }^{3-}$ ions exists in solution and could possibly have been coprecipitated with pyrophosphate. Comparison with $\mathrm{CaH}_{2} \mathrm{P}_{2} \mathrm{O}_{7}$ indicates that $v_{1} \mathrm{PO}$, a vibration specific for the $\mathrm{P}-$ $\mathrm{O}$ bond symmetric elongation, would be detected around 1220 $\mathrm{cm}^{-1}$ (Fig. 4b). ${ }^{15}$

A thermogravimetric analysis was performed to study the stability of the m-CPPT $\beta$ and u-CPP phases at low temperature (around $30{ }^{\circ} \mathrm{C}$ ) and at higher temperature (up to $500{ }^{\circ} \mathrm{C}$ ).

A weight loss approximately corresponding to one $\mathrm{H}_{2} \mathrm{O}$ molecule $\left(0.9 \mathrm{H}_{2} \mathrm{O}\right)$ was observed for the m-CPPT $\beta$ phase, during the preliminary plateau at $30{ }^{\circ} \mathrm{C}$, whereas no significant weight loss was measured for the u-CPP phase at low temperature (Fig. 5a). However, at higher temperature, the two phases synthesised showed quite similar thermogravimetric curves up to $500{ }^{\circ} \mathrm{C}$, with the same weight loss: $3 \mathrm{H}_{2} \mathrm{O}$ molecules, approximately (Fig. 5b).

The weight loss between 80 and $110{ }^{\circ} \mathrm{C}$ corresponds to $2 \mathrm{H}_{2} \mathrm{O}$ whereas the one between 250 and $500{ }^{\circ} \mathrm{C}$ corresponds to $1 \mathrm{H}_{2} \mathrm{O}$ (two steps). These ranges of temperature are consistent with the data already published. ${ }^{8}$

Finally, the total loss of water was around $4 \mathrm{H}_{2} \mathrm{O}$ as expected for $\mathrm{m}$-CPPT $\beta$ and $3 \mathrm{H}_{2} \mathrm{O}$ for $\mathrm{u}$-CPP. It appears that u-CPP is potentially a trihydrated calcium pyrophosphate; the similarities observed with $\mathrm{m}$-CPPT $\beta$ during the second part of the experiment reinforce the assumption that there could be a link between the two phases.
Fig. 6 shows the evolution of the XRD diagram of the $\mathrm{m}$-CPPT $\beta$ phase when treated for $1 \mathrm{~h}$ at $50{ }^{\circ} \mathrm{C}$. We observed that after this treatment the pattern corresponds to that of u-CPP (see Fig. 2 and 6) and there is no structural difference
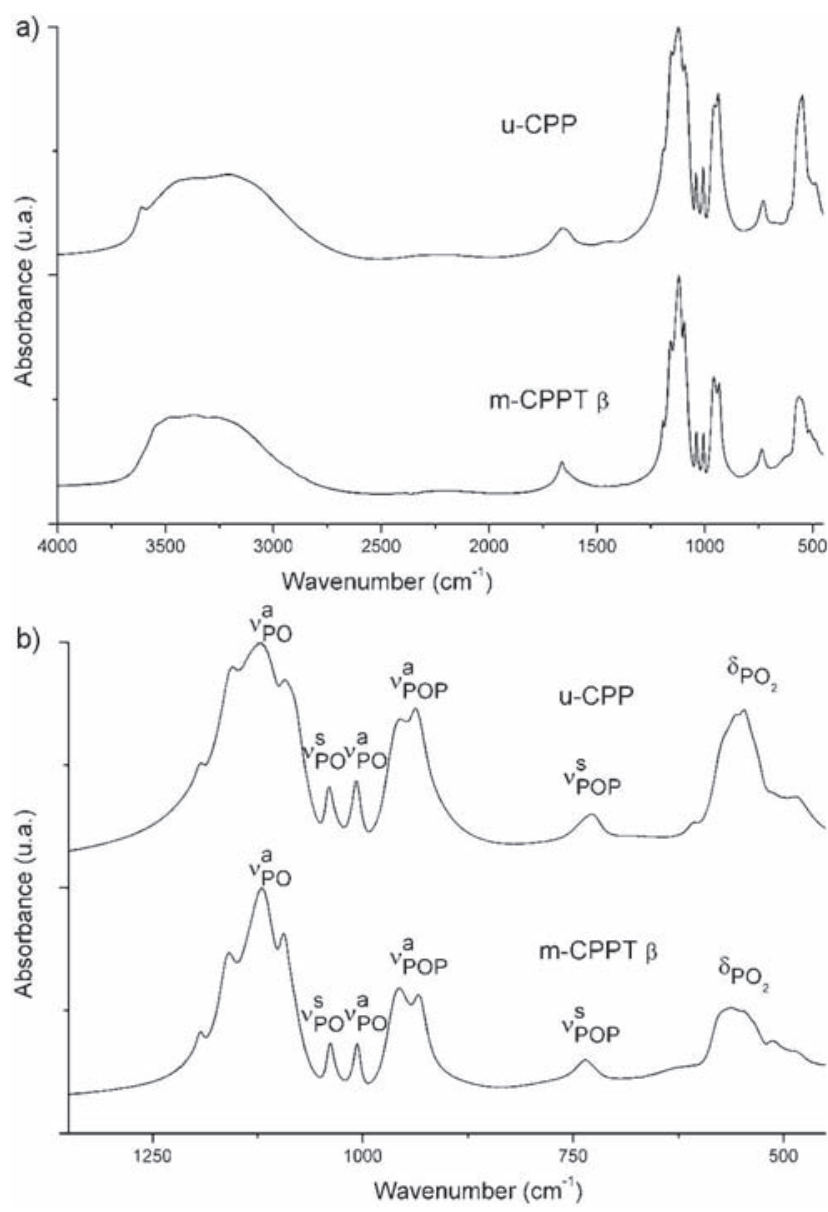

Fig. 4 FTIR spectra of the two hydrated calcium pyrophosphate phases synthesised in the same conditions but using two different setups: $m$-CPPT $\beta$ and U-CPP: a) $4000-400 \mathrm{~cm}^{-1}$ domain; b) $1300-500 \mathrm{~cm}^{-1}$ domain. 

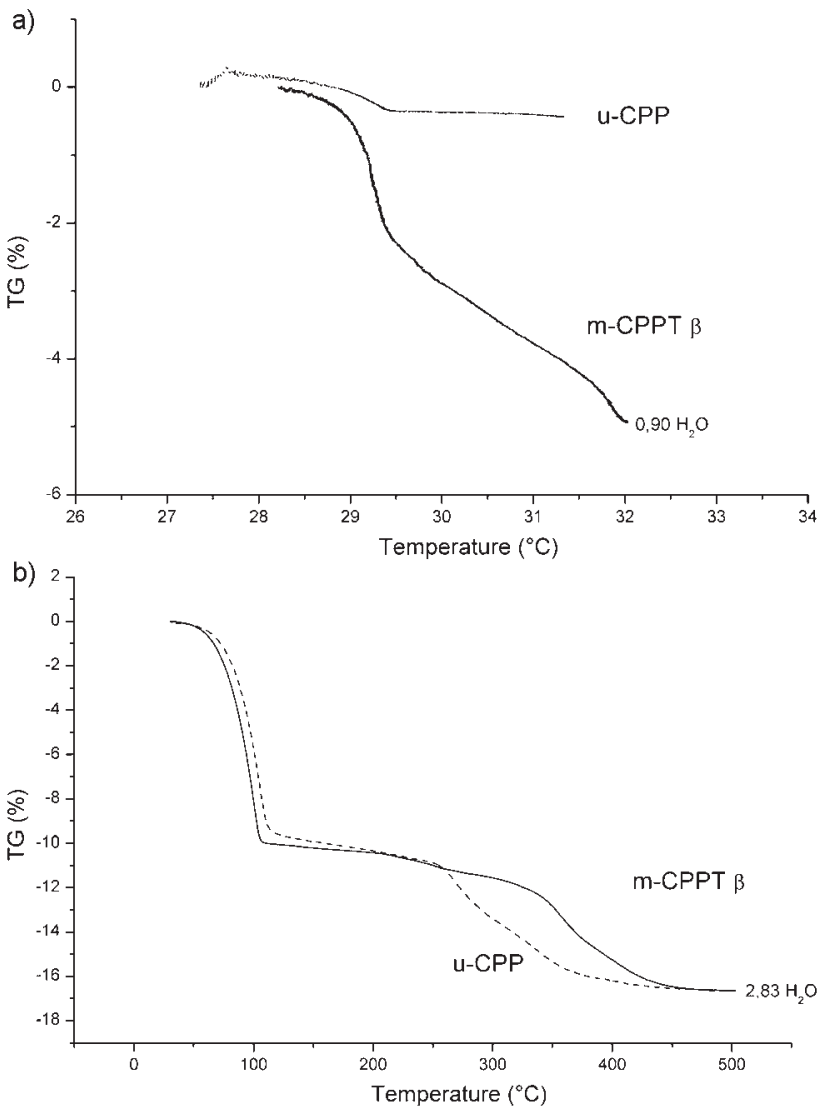

Fig. 5 TGA of the two hydrated calcium pyrophosphate phases ( $m$-CPPT $\beta$ and $\mathrm{u}$-(PP) synthesised under the same conditions but using two different setups: a) at low temperature (up to $32{ }^{\circ} \mathrm{C}$ ) and b) at high temperature (up to $500{ }^{\circ} \mathrm{C}$ ).

observed between the u-CPP phases obtained by dry synthesis (dehydration of m-CPPT $\beta$ ) and wet synthesis, direct precipitation, and no trace of other compounds was found by comparison between the two diagrams.

This experiment confirms the link between the u-CPP and m-CPPT $\beta$ phases synthesised using the same conditions of temperature and $\mathrm{pH}$. As an explanation, a more efficient and powerful stirring in the tank reactor could influence the size and the organisation of the crystals ${ }^{9}$ and explain the difference in hydration state of the precipitated phases. According to the width of XRD peaks observed on u-CPP phase, the crystals synthesised in a stirred tank reactor were thinner or had a lower crystallinity compared to the crystals obtained by dehydration. These conditions could shift the temperature of dehydration, which was reported close to room temperature. A similar mechanism could explain the differences observed by TGA around $300{ }^{\circ} \mathrm{C}$. The second step of dehydration started at lower temperature for $\mathrm{u}$-CPP phase even if at this temperature these two phases were similar.

However the main difference between the two u-CPP phases prepared either in dry state by dehydration of m-CPPT $\beta$ or by direct aqueous precipitation in stirred tank reactor is their stability at room temperature and atmosphere. When the $\mathrm{u}-\mathrm{CPP}$ phase obtained by dry synthesis is left at ambient temperature, we can observe that after 15 min (Fig. 6) it is

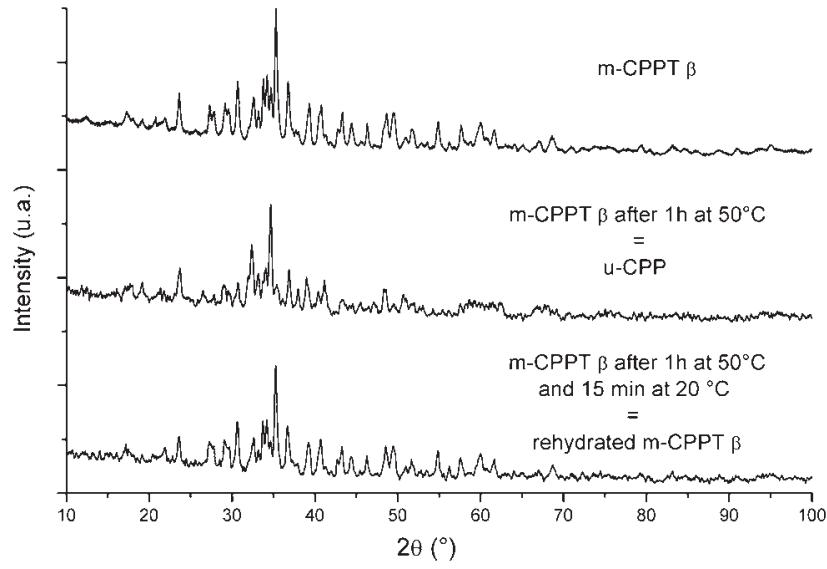

Fig. 6 XRD patterns of $\mathrm{m}$-CPPT $\beta$ phase as synthesised, after heating $1 \mathrm{~h}$ at $50{ }^{\circ} \mathrm{C}$ and then $15 \mathrm{~min}$ at $20^{\circ} \mathrm{C}$.

reversibly transformed into the m-CPPT $\beta$ phase, probably by capturing ambient air humidity to rehydrate whereas the $\mathrm{u}-\mathrm{CPP}$ phase obtained in wet media can be kept for more than 3 months without alteration. The smaller crystal size of the u-CPP crystals obtained by wet synthesis would suggest an inverse reactivity and the experimental observation related to the re-hydration properties of these phases which highlights the effect of the conditions of synthesis on the crystals properties, has not yet received a satisfactory explanation.

The u-CPP phase can be considered as highly metastable, consequently small changes in the morphology could greatly influence its reactivity. Crystals formed in joints are reported to have various sizes depending on the joint type: from around $1 \mu \mathrm{m}$ up to $20 \mu \mathrm{m}$ for knee and 0.06 to $0.3 \mu \mathrm{m}$ for temporomandibular joint. ${ }^{16,17}$ Even if m-CPPT $\beta$ crystals were never observed in vivo, they could be formed as metastable intermediate and the dehydration described in the present paper could occur during the treatment of the synovial fluid specimen and may affect the identification of the CPP phases.

These preliminary results on the characterisation of the two phases synthesised suggest that $\mathrm{u}$-CPP phase could be a trihydrated calcium pyrophosphate metastable phase derived from the tetrahydrated m-CPPT $\beta$.

In order to compare with another m-CPPT $\beta$ derived compound, attempts were made to synthesise h-CPPD, a phase produced by dehydration of m-CPPT $\beta .^{2}$ However the product obtained was characterised as a monohydrate CPP, with a XRD diagram different from h-CPPD and u-CPP patterns. In present study, no comparison could therefore be established between h-CPPD and u-CPP.

\section{Calculation}

Further investigations were performed to better define the $\mathrm{u}$-CPP phase. Calculations on the structure of the u-CPP phase were made using the m-CPPT $\beta$ structure as reference structure. The structure of the m-CPPT $\beta$ phase was elucidated by Balić-Žunić et $a l^{4}{ }^{4}$ This phase presents a layered structure with the water molecules on the surface of layers. The platelet morphology observed for m-CPPT $\beta$ crystals (Fig. 3a) is in 
Table 2 Calculated cell parameters (Jana2006 ${ }^{12}$ ) of $u$-CPP and m-CPPT $\beta$ phases compared to published data for cell parameters of m-CPPT $\beta^{4}$

\begin{tabular}{llllll}
\hline & $a(\AA)$ & $b(\AA)$ & $c(\AA)$ & $\beta\left(^{\circ}\right)$ & $\alpha=\gamma\left({ }^{\circ}\right)$ \\
\hline u-CPP & $11.399(6)$ & $7.409(2)$ & $10.859(3)$ & $110.16(1)$ & 90.00 \\
m-CPPT & $12.290(4)$ & $7.518(4)$ & $10.774(6)$ & $112.54(1)$ & 90.00 \\
$\beta$ synthesised & & & & & \\
m-CPPT $\beta^{4}$ & $12.287(6)$ & $7.511(3)$ & $10.775(5)$ & $112.54(1)$ & 90.00
\end{tabular}

accordance with this organisation. In addition, it has been reported that one of the four water molecules of the m-CPPT $\beta$ phase, referred as OW4, does not coordinate any Ca atom and is held in the structure only by weak hydrogen bonding to other $\mathrm{O}$ atoms. This position suggests that weaker bonds hold this molecule in the structure and could explain the loss of one $\mathrm{H}_{2} \mathrm{O}$ molecule below $50{ }^{\circ} \mathrm{C}$ (Fig. 5a) observed by TGA. This conclusion was previously suggested by Balić-Žunić et al.

The preliminary results of calculations of the cell parameters for the u-CPP phase are reported in Table 2 and the corresponding XRD data for $\mathrm{u}-\mathrm{CPP}$ are presented in Table 3 with the assumed indexing.

$\mathrm{u}$-CPP has the same crystal symmetry as m-CPPT $\beta$, with nearly equal $b$ and $c$ lattice parameters. A larger difference is observed for the $\beta$ angle and the $a$ parameter. The difference is probably a consequence of the dehydration and reorganisation of the remaining water molecules. Indeed, the labile water molecule and two other structural water molecules are contained on a (100) plane of the m-CPPT $\beta$ structure, which represents also the most extended surface plane of the crystals. $^{4}$

We can thus expect a larger impact of dehydration and the reorganisation phenomenon on the $a$-axis than on the other lattice parameters. Moreover according to the FTIR spectrocopy analyses, the environments of pyrophosphate ions seem slightly affected by this reorganisation.

Although the atomic configuration of u-CPP phase was not determined with enough accuracy, a first approximation was to consider its structure as a modified m-CPPT $\beta$ structure without the oxygen atom referred as OW4 by Balić-Žunić et al. ${ }^{4}$

Table 3 Peak positions and indexing of u-CPP powder diffraction data (most intense peaks with intensities greater than 10\%)

\begin{tabular}{lll}
\hline$d(\AA)$ & Intensity & $h k l$ \\
\hline 10.7099 & 1000 & 100 \\
5.7643 & 121 & $11-1$ \\
4.3608 & 181 & $11-2 / 210$ \\
3.5745 & 153 & $112 / 300$ \\
3.3905 & 140 & $31-1$ \\
3.2561 & 128 & $11-3$ \\
3.2182 & 283 & $310 / 31-2$ \\
3.1418 & 151 & $21-3$ \\
3.0538 & 168 & $12-2 / 220$ \\
3.0027 & 543 & 022 \\
2.8281 & 213 & 311 \\
2.7497 & 106 & 122 \\
2.6804 & 201 & 400 \\
2.5437 & 164 & $302 / 11-4$ \\
2.1830 & 140 & $41-4 / 22-4$
\end{tabular}

It should be noted that several structures of calcium pyrophosphates are not resolved, including m-CPPD, a phase encountered in some arthritic joints.

The reorganisation of pyrophosphate and calcium ions in the structure could change the phlogistic potential of calcium pyrophosphate crystals. A proposed mechanism of inflammation in crystal-induced diseases is dependent on the rupture of the lysosome phospholipid membrane and induced by pyrophosphate species on the surface of the crystals. ${ }^{18,19}$ Thus, the structure of the crystals as well as the surface is important in determining the inflammatory potential. ${ }^{20}$

Even if the m-CPPT $\beta$ phase has never been observed in vivo, its role as precursor of $\mathrm{m}$-CPPD and $\mathrm{t}-\mathrm{CPPD}$ has been described in vitro. ${ }^{2}$ As well as m-CPPT $\beta$, u-CPP could be an intermediate of CPPD formation under specific conditions. Finally a description of the $\mathrm{u}$-CPP structure could increase the knowledge about calcium pyrophosphate interactions in vivo.

\section{Conclusions}

A method was set up to prepare pure m-CPPT $\beta$ phase at $25{ }^{\circ} \mathrm{C}$ by double decomposition between a potassium pyrophosphate solution and a calcium nitrate solution in an aqueous buffered solution ( $\mathrm{pH}$ 4.5) magnetically stirred in an Erlenmeyer flask. This method is fast, reliable and reproducible compared with methods of preparation already published.

For the first time, we showed that these conditions (temperature, $\mathrm{pH}$ ) can also enable obtaining a pure unknown hydrated calcium pyrophosphate phase (u-CPP), just by changing the reaction vessel (stirred tank reactor). Fine characterisation of the u-CPP phase using complementary analytical techniques and calculations suggest that it is a highly metastable trihydrated monoclinic calcium pyrophosphate derived from the structure of m-CPPT $\beta$. However the structure could not be determined and the structural refinement of the powder diffraction pattern is still under investigation.

This work contributes to clarifying the mechanism by which CPP crystals form in vitro and in vivo, and this metastable trihydrated CPP phase (u-CPP) could be an intermediate of CPPD crystal deposit formation in weightbearing articulation.

\section{Acknowledgements}

The authors thank the Institut National Polytechnique de Toulouse (PRECIPYCA project - BQR INPT 2011) and the Centre National de la Recherche Scientifique (CalArthros project - "Longévité et Vieillissement 2010" CNRS interdisciplinary program) for supporting this research work.

\section{References}

1 N. S. Mandel, Acta Crystallogr., Sect. B: Struct. Crystallogr. Cryst. Chem., 1975, 31, 1730-1734. 
2 G. S. Mandel, K. M. Renne, A. M. Kolbach, W. D. Kaplan, J. D. Miller and N. S. Mandel, J. Cryst. Growth, 1988, 87, 453-462.

3 N. L. Davis, G. S. Mandel, N. S. Mandel and R. E. Dickerson, J. Crystallogr. Spectrosc. Res., 1985, 15, 513-521.

4 T. Balić-Žunić, M. R. Christoffersen and J. Christoffersen, Acta Crystallogr., Sect. B: Struct. Sci., 2000, 56, 953-956.

5 K. P. H. Pritzker, Calcium pyrophosphate crystal formation and dissolution in Calcium Phosphate in Biological and Industrial Systems, Kluwer Academic Publishers, 1998, pp. 296-301.

6 P. J. Grove, R. M. Wilson, P. A. Dieppe and R. P. Shellis, J. Mater. Sci.: Mater. Med., 2007, 18, 1355-1360.

7 E. H. Brown, J. R. Lehr, J. P. Smith and A. W. Frazier, J. Agric. Food Chem., 1963, 11(3), 214-222.

8 M. R. Christoffersen, T. Balić-Žunić, S. Pehrson and J. Christoffersen, J. Cryst. Growth, 2000, 212, 500-506.

9 N. Bénet, H. Muhr, E. Plasari and J. M. Rousseaux, Powder Technol., 2002, 128, 93-98.

10 J. W. Mullin, Crystallization, ButterworthsLondon, 2nd edn, 1972.

11 C. Herman, V. Gelbgras, V. Halloin and B. Haut, Proceedings of European Congress of Chemical Engineering, 2007.
12 V. Petricek, M. Dusek and L. Palatinus, Jana2006, The crystallographic computing system, Institute of Physics, Praha, Czech Republic, 2006.

13 C. Slater, D. Laurencin, V. Burnell, M. E. Smith, L. M. Grover, J. A. Hriljac and A. J. Wright, J. Mater. Chem., 2011, 21, 18783-18791.

14 R. B. Stockbridge and R. Wolfenden, J. Biol. Chem., 2011, 286(21), 18546-18546.

15 J. L. Savio, PhD thesis, Contribution à l'étude des pyrophosphates de calcium hydrates et de leurs propriétés phlogogènes, Institut National Polytechnique de Toulouse, Toulouse, 1982.

16 N. N. Kohn, R. E. Hughes, D. J. McCarty and J. S. Faires, Ann. Intern. Med., 1962, 56, 738-745.

17 L. C. Dijkgraaf, R. S. B. Liem, L. G. M. de Bont and G. Boering, Osteoarthritis Cartilage, 1995, 3, 35-45.

18 N. S. Mandel, Arthritis Rheum., 1976, 19, 439-445.

19 A. Wierzbicki, P. Dalal, J. D. Madura and H. S. Cheung, J. Phys. Chem. B, 2003, 107, 12346-12351.

20 M. Roch-Arveiller, R. Legros, B. Chanaud, O. Muntaner, S. Strzalko, A. Thuret, D. A. Willoughby and J. P. Giroud, Biomed. Pharmacother., 1990, 44, 467-474. 